coloproctology $2018 \cdot 40: 246$

https://doi.org/10.1007/s00053-018-0269-1

(C) Springer Medizin Verlag GmbH, ein Teil von Springer Nature 2018

CrossMark

\title{
F. Aigner
}

Campus Mitte und Virchow-Klinikum, Chirurgische Klinik für Charité Universitätsmedizin Berlin, Berlin, Deutschland

\section{Hämorrhoiden}

Die folgenden fünf unter dem Leitthema „Hämorrhoiden“ zusammengefassten Artikel sollen eine Art Refresher zu einem altbewährten Thema aus gegebenem Anlass der Aktualisierung der S3-Leitlinie unter der Federführung der Deutschen Gesellschaft für Koloproktologie bieten.

\section{》) Das Hämorrhoidalleiden wurde in letzter Zeit weniger behandelt als andere Themen}

Tatsächlich wurde das Hämorrhoidalleiden in letzter Zeit auf den Jahreskongressen der nationalen und internationalen koloproktologischen Fachgesellschaften weniger behandelt im Vergleich zu anderen Themen wie Innovationen in der Therapie des Analfistelleidens oder individualisierte Therapie des kolorektalen Karzinoms.

\section{》) Insbesondere die ambulante Therapie des Hämorrhoidalleidens soll beleuchtet werden}

Um dem Anschein fehlender Innovationen in der Therapie des Hämorrhoidalleidens entgegenzuwirken, haben sich im vorliegenden Band Expertinnen und Experten dem Thema „Alte Zöpfe oder neue Ansätze“ gewidmet und beleuchten insbesondere auch das Thema ambulante Therapie des Hämorrhoidalleidens in Zeiten der drastischen Verkürzung der Krankenhausliegedauer und des zunehmenden Leistungsdrucks an heimischen Kliniken. Dieses Leitthema soll aber auch in erster Linie jungen Koloproktologinnen und Koloproktologen als Vademe- cum oder neudeutsch Pocketguide für die tägliche Praxis dienen und erfüllt in weiterer Folge eine Vorstellung der mit Ende dieses Jahres zu erwartenden Aktualisierung der S3-Leitlinie.

\section{Korrespondenzadresse}

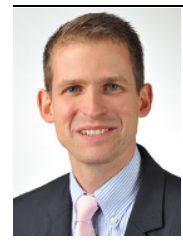

PD Dr. F. Aigner

Campus Mitte und Virchow-Klinikum, Chirurgische Klinik für Charité Universitätsmedizin Berlin Charitéplatz 1, 10117 Berlin, Deutschland felix.aigner@charite.de

Interessenkonflikt. F. Aigner gibt an, dass kein Interessenkonflikt besteht. 